\title{
Laminar Localization, Morphology, and Physiological Properties of Pyramidal Neurons that Have the Low-Threshold Calcium Current in the Guinea-Pig Medial Frontal Cortex
}

\author{
Elvira de la Peña and Emilio Geijo-Barrientos \\ Departamento de Fisiología and Instituto de Neurociencias, Universidad de Alicante, E-03080 Alicante, Spain
}

\begin{abstract}
One of the several types of ionic currents present in central neurons is the low-threshold, or T-type calcium current (LTCC). This current is responsible for the firing of low-threshold calcium spikes (LTS) and participates in the generation of rhythmic activity and bursts of action potentials in several brain nuclei. We have studied the distribution and properties of pyramidal neurons recorded from the guinea-pig medial frontal cortex that have this calcium current. Pyramidal neurons were recorded in an in vitro slice preparation using either current clamp or singleelectrode voltage-clamp recording. Pyramidal neurons that generated LTS or had the LTCC were found only between 500 $\mathrm{mm}$ from the pial surface and the white matter (approximately layers V/VI) and were absent in more superficial layers. All pyramidal neurons that fired LTS or had the LTCC were characterized as regular spiking and had some important morpho-
\end{abstract}

logical and physiological differences from the rest of the pyramidal neurons studied. This group of neurons had shorter and less complex apical dendritic arbors, fired action potentials of lower amplitude and longer duration, and were the only type of pyramidal neurons able to generate bursts of action potentials. In addition, the inhibitory synaptic potentials elicited by stimulation of layer I were more powerful in this group of neurons. This research provides new evidence for the presence of the LTCC in subsets of cortical pyramidal neurons, which have specific and well defined morphological and physiological properties.

Key words: calcium currents; cerebral cortex; pyramidal neurons; synaptic potentials; calcium spikes; frontal cortex; intracellular recording; single-electrode voltage-clamp
Neurons differ in the types and distribution of specific ion channels present on their somata and dendrites. These intrinsic membrane differences are manifest in the shape of individual action potentials, lead to distinctive temporal patterns of repetitive firing, and determine to a large extent the way individual neurons transform synaptic input into spike output (Llinás, 1988; McCormick, 1990). In the cerebral cortex, neurons have been classified according to their intrinsic electrophysiological responses, and these neuronal types have been correlated with distinct morphological types (Connors et al., 1982; McCormick et al., 1985; Chagnac-Amitai et al., 1990) (for review, see Connors and Gutnick, 1990).

The type and distribution of calcium currents in the somatodendritic neuronal membrane are important determinants of their intrinsic electrical properties. In spite of their presumed importance, and in marked contrast to other neuronal cell types (Hess, 1990; McCleskey, 1994), the properties of voltage-gated calcium currents in neurons of the mammalian cortex have not been fully characterized. This perhaps is not surprising, because the cellular heterogeneity of the cortex and the difficulties associated with identifying specific cell types have limited the study of the intrinsic membrane properties of cortical neurons. Nevertheless, the presence of lowthreshold and several types of high-threshold calcium currents has been reported in acutely isolated pyramidal neurons (Sayer et al.,

\footnotetext{
Received March 5, 1996; revised June 3, 1996; accepted June 5, 1996.

This work was supported by Grant PB92-0347 from the DGICYT (Spain). We are grateful to Drs. R. Gallego and J. V. Sánchez-Andrés for helpful comments on this manuscript and to Drs. P. Berbel and A. Fairén for advice on morphology. We also thank Messrs. S. Moya and A. Pérez-Vegara for their expert technical assistance.

Correspondence should be addressed to Dr. Emilio Geijo-Barrientos, Departamento de Fisiología, Universidad de Alicante, Apartado 374, E-03080 Alicante, Spain.

Copyright (C) 1996 Society for Neuroscience $0270-6474 / 96 / 165301-11 \$ 05.00 / 0$
}

1990; Brown et al., 1993; Sayer et al., 1993; Brown et al., 1994) and in intact pyramidal neurons recorded from cortical slices (Franz et al., 1986; Sutor and Zieglgänsberger, 1987). One of these calcium currents, the low-threshold (or T type) calcium current (LTCC), plays an important role in generating bursts of action potentials and slow rhythmic activity in structures such as the thalamus and inferior olive (for review, see Steriade and Llinás, 1988). LTCC is present only in specific neuronal types in the mammalian CNS (Llinás, 1988). An issue of importance is to study the presence of this calcium current in areas of the CNS such as the cerebral cortex, where multiple neuronal types are present, and to determine whether it is present in all neurons or whether it is restricted to some particular layers or neuronal groups.

This study was undertaken to examine the presence of LTCCs in pyramidal neurons of guinea-pig medial frontal cortex (MFC) and to determine the laminar distribution and the physiological and morphological characteristics of those in which it was present.

Part of this work has been presented in abstract form (GeijoBarrientos and de la Peña, 1995).

\section{MATERIALS AND METHODS}

The experiments were performed on slices of frontal cortex prepared from young adult guinea-pigs (150-350 gm; 3-6 weeks) following methods described elsewhere (Geijo-Barrientos and Pastore, 1995). In brief, the animals were anesthetized with sodium pentobarbital $(30-35 \mathrm{mg} / \mathrm{kg}$, i.p.), decapitated, and their brains quickly excised and submerged in ice-cold saline [composition (in mM): $124 \mathrm{NaCl}, 5 \mathrm{KCl}, 1.2 \mathrm{KH}_{2} \mathrm{PO}_{4}, 2.4$ $\mathrm{CaCl}_{2}, 1.3 \mathrm{MgSO}_{4}, 26 \mathrm{NaHCO}_{3}, 10$ glucose, $\mathrm{pH} 7.4$, when saturated with $95 \% \mathrm{O}_{2}+5 \% \mathrm{CO}_{2}$ ]. A block of tissue, which included the frontal pole of the brain, was dissected out, and 3-4 slices $250-350 \mu \mathrm{m}$ thick were cut from it in a coronal plane using a Vibratome (Pelco, Redding, CA). The slices were stored in small glass vials where the tissue was submerged in saline continuously bubbled with $95 \% \mathrm{O}_{2}+5 \% \mathrm{CO}_{2}$ at room tempera- 
ture. The slices were incubated in these vials for at least $1.5 \mathrm{hr}$, allowing the tissue to stabilize before recordings were performed.

\section{Intracellular recordings and single-electrode voltage-clamp}

A single slice was placed in the recording chamber where it was kept submerged in saline flowing at a rate of $1-2 \mathrm{ml} / \mathrm{min}$ at $33-35^{\circ} \mathrm{C}$. The recording chamber was mounted on the stage of an upright microscope fitted with a calibrated eyepiece; under a total magnification of $100 \times$, it was possible to measure the position of the microelectrode's tip relative to the pial surface and the white matter. Intracellular recordings were performed with glass microelectrodes pulled from thick wall borosilicate glass $(1.0 \mathrm{~mm}$ outer diameter, $0.5 \mathrm{~mm}$ wall thickness) on a Sutter P-87 puller (Sutter Instruments, Novato, CA) and filled with $3 \mathrm{~m}$ K-acetate (80-150 $\mathrm{M} \Omega$ ); in some voltage-clamp experiments, we used electrodes filled with $2 \mathrm{M} \mathrm{CsCl}$. Intracellular signals were recorded with an Axoclamp 2A (Axon Instruments, Foster City, CA) operating either in the bridge mode for current-clamp recording or in the discontinuous singleelectrode voltage-clamp mode (dSEVC); in the latter case, we adjusted the amplifier settings following the procedure suggested by Finkel and Redman (1985). During dSEVC recordings, the output signal of the amplifier headstage was continuously monitored on a separate oscilloscope, and the switching frequency, capacitance neutralization, phase, and gain were adjusted for optimal settlement of the electrode voltage transients. After reducing to a minimum the electrode stray capacitance, the switching frequency was set at $3-4 \mathrm{kHz}$, and the gain was increased up to $0.8-2.5 \mathrm{nA} / \mathrm{mV}$. The recordings obtained under dSEVC were accepted only if the voltage transient in the electrode settled entirely after each current-injecting cycle and if the membrane potential did not deviate $>3-4 \mathrm{mV}$ from the command potential at the peak of the inward transient current described in Results; this deviation was considered acceptable in relation to the small amplitude of these currents $(\sim 0.6 \mathrm{nA})$. Although the use of the above criteria resulted in a relatively small number of cells recorded under dSEVC, all of them were located at all depths within the cortex, and we did not find any layer-specific bias in the quality of the voltage clamp.

Synaptic potentials were elicited using bipolar stimulation electrodes made of Teflon-coated platinum wire (150 $\mu \mathrm{m}$ diameter) positioned on the pial surface of the slice or directly over layer I. The duration of the stimulus was fixed at either 0.2 or $0.5 \mathrm{msec}$, and the strength was adjusted to elicit synaptic potentials of maximum amplitude.

The drugs used in this work were tetrodotoxin (TTX) and tetraethylammonium chloride (TEA) from Sigma (St. Louis, MO), nimodipine, $\omega$-conotoxin GVIA, and $\omega$-conotoxin MVIIC from RBI (Natick, MA), and $\omega$-agatoxin IVA from Alomone Labs (Jerusalem, Israel). Nimodipine was made up as a $50 \mathrm{~mm}$ stock solution in dimethylsulfoxide and dissolved in extracellular solution to its final concentration. TTX, TEA, and nimodipine were applied dissolved in extracellular solution at the concentrations shown. Stocks of $\omega$-conotoxin GVIA and MVIIC (100 $\mu \mathrm{M})$ and $\omega$-agatoxin $(1 \mu \mathrm{M})$ were prepared in saline, and $0.1 \%$ cytochrome $c$ was added to the stock of $\omega$-agatoxin to prevent its absorption on the walls of the container. A solution containing a mixture of $20 \mu \mathrm{M} \omega$-conotoxin GVIA and MVIIC and $200 \mathrm{nM} \omega$-agatoxin was made in extracellular solution from the above stocks; this blocking cocktail was applied for at least $3 \mathrm{~min}$ by a puffer pipette (10-20 $\mu \mathrm{M}$ of tip diameter) placed over the recording site close to the slice surface; the efflux from the pipette was oriented toward the pial surface and in parallel to the flow of the bulk of the extracellular solution in the recording chamber. The composition of the $\mathrm{Ca}^{2+}$-free extracellular solution was the same as the extracellular solution given above, except that $\mathrm{CaCl}_{2}$ was omitted, the concentration of $\mathrm{MgSO}_{4}$ was increased to $3.7 \mathrm{~mm}$ and, in some experiments, $1 \mathrm{~mm}$ EGTA was added. $\mathrm{Ni}^{2+}$ was added to the extracellular solution as $\mathrm{NiCl}_{2}$.

The recorded signals were stored on digital audiotape (Biological, Claix, France) and subsequently digitized using an analog-to-digital converter and commercial software (Cambridge Electronic Design, Cambridge, UK); the recordings obtained under voltage-clamp were digitized on-line using computer software that controlled data acquisition and the generation of voltage pulses. Numerical values are given as mean \pm SEM (number of cases).

\section{Intracellular staining with Neurobiotin}

Neurobiotin was used to identify the morphology of recorded cells (Vector Laboratories, Burlingame, CA). Microelectrode tips were filled with $2-4 \%$ Neurobiotin in $1 \mathrm{M} \mathrm{KCl}$, and the tracer was injected using depolarizing current pulses $(0.2-0.4 \mathrm{nA}, 450 \mathrm{msec}, 1 \mathrm{~Hz}$ for 3-15 min).
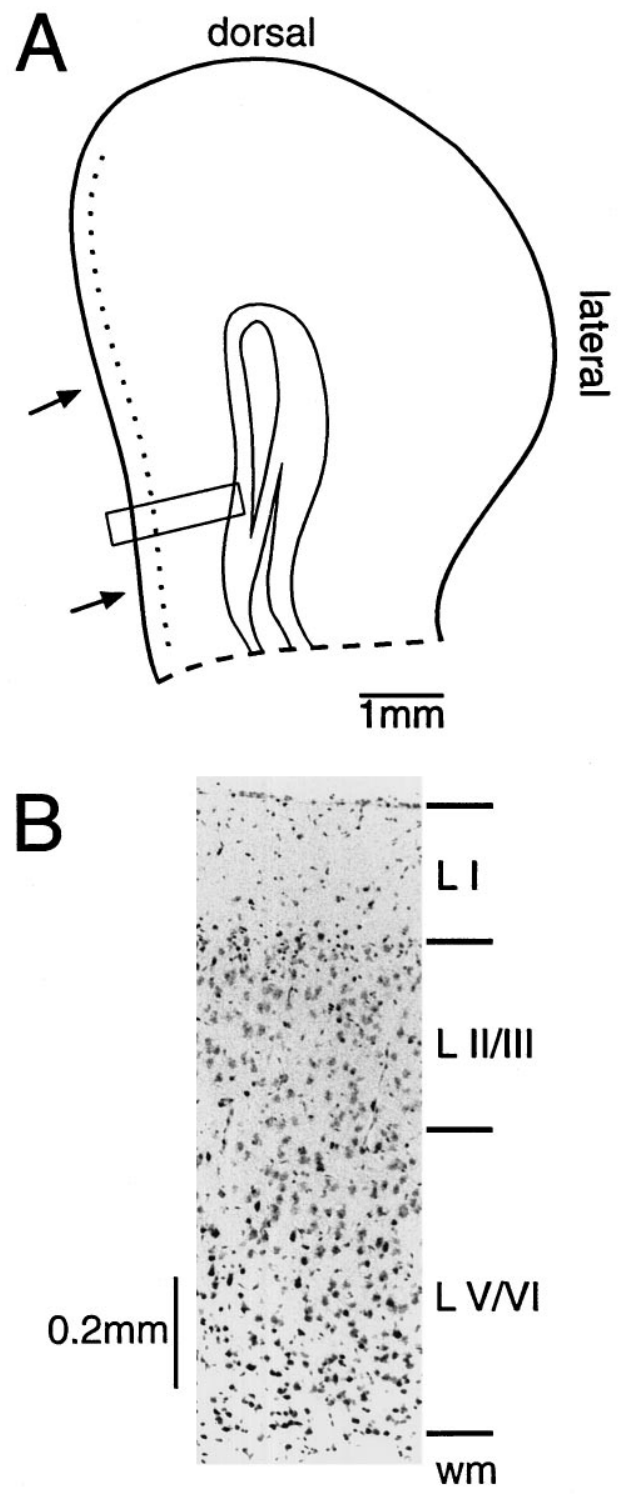

Figure 1. Guinea-pig medial frontal cortex. $A$, Drawing of a coronal slice made from the frontal pole of the guinea-pig brain; the dotted line shows the limit of layer I. The ventral part of the slice was cut away (dashed line), and the arrows show the medial frontal cortex, where the intracellular recordings were obtained. $B$, Nissl staining of the MFC; the approximate limits between layers are indicated. $w m$, White matter. The cortical area shown in $B$ corresponds approximately to the area marked with a rectangle in $A$.

Slices were fixed by overnight submersion in $4 \%$ paraformaldehyde PBS (0.1 M, pH 7.4). After $\mathrm{H}_{2} \mathrm{O}_{2}(0.3 \%)$ and Triton X-100 (0.6\%) pretreatment, the slices were then processed by incubation in a 1:100 dilution of $\mathrm{ABC}$ complex (Vector) and by a $0.03 \%$ solution of 3,3-diaminobenzidine and $0.005 \% \mathrm{H}_{2} \mathrm{O}_{2}$. The stained neurons were drawn using a video camera coupled to the microscope and suitable software (Neurograph program from Microptic, Barcelona, Spain).

\section{RESULTS}

\section{General electrophysiological properties}

The results presented here are from stable intracellular recordings obtained from guinea-pig MFC neurons. Figure $1 A$ shows diagrammatically the cortical area of a guinea-pig frontal slice where the recordings were obtained; this cortical area was 
A1
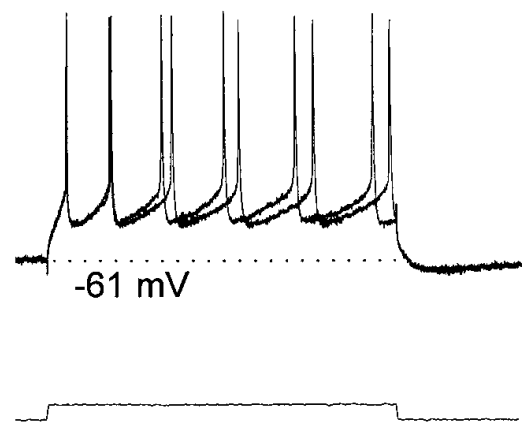

B1

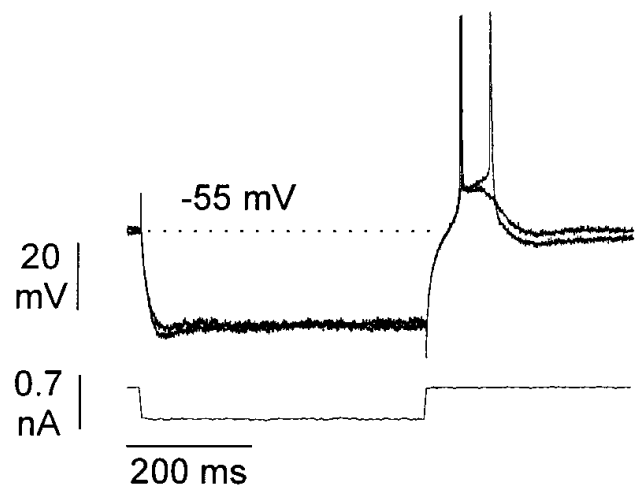

A2
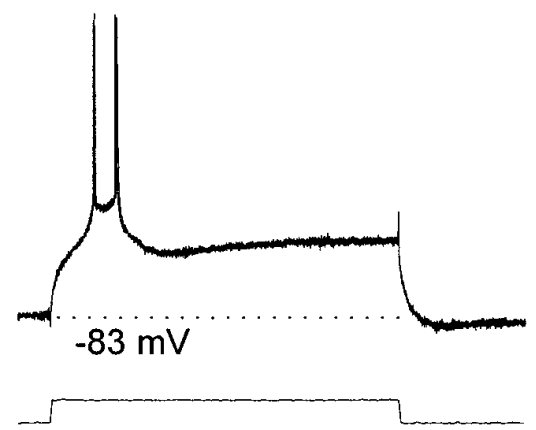

B2

TTX
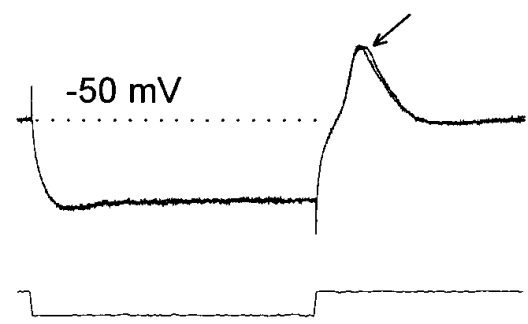

Figure 2. Electrophysiological properties of MFC neurons. $A$, Responses of a neuron (recording electrode at $790 \mu \mathrm{m}$ from the pial surface) to depolarizing current pulses (bottom traces) applied from resting membrane potential $(A 1)$ and from a hyperpolarized level (A2); this neuron fired tonically with frequency adaptation from the resting membrane potential (A1) and a doublet of action potentials from a hyperpolarized membrane potential $(A 2)$. B , Responses of a different cell (recording electrode at 860 $\mu \mathrm{m}$ from the pia) to hyperpolarizing current pulses in control extracellular solution $(B 1)$ and in the presence of $1 \mu \mathrm{M}$ TTX (B2); note the clear LTS in $B 2$ (arrow). Two consecutive sweeps are superimposed in all panels. The membrane potential is shown in each panel. Calibration bars in $B 1$ apply to all records. agranular (Fig. $1 B$ ) and very similar to rat anterior cingulate cortex and infralimbic cortex (Vogt and Peters, 1981; Zilles and Wree, 1985). The 136 cells recorded had resting membrane potentials of $-58 \pm 0.54 \mathrm{mV}$ and input resistances (measured from their response to small hyperpolarizing current pulses) of $53 \pm 2.5 \mathrm{M} \Omega$. The action potential amplitudes were $75 \pm 0.84$ $\mathrm{mV}$ with a duration at half amplitude of $1.5 \pm 0.21 \mathrm{msec}$. Their general electrophysiological properties, studied from their responses to the injection of depolarizing and hyperpolarizing current pulses, are illustrated in Figure 2. The neurons had electrical responses similar to the regular spiking (RS) class of cells described previously in guinea-pig and rat neocortex (Connors et al., 1982; McCormick et al., 1985; Chagnac-Amitai et al., 1990; Connors and Gutnick, 1990). The electrophysiological hallmark of this cell class is tonic firing with frequency adaptation in response to long suprathreshold current pulses (Fig. 2A1). Of the cells recorded, only $2 \%$ had responses similar to fast spiking (FS) or intrinsically bursting (IB) cells; these cells were excluded from the analysis. Although none of the studied neurons produced bursts of action potentials from the resting membrane potential, in many cells we found a response generated from negative membrane potentials that was very similar to the "rebound" response generated by the presence of low-threshold calcium spikes (LTS) in cells from the thalamus or inferior olive (Llinás and Yarom, 1981; Jahnsen and Llinás, 1984). This response consisted of one or two action potentials firing on top of a slow depolarization and appeared only when the membrane potential was held negative to -65 or $-70 \mathrm{mV}$ for $>200-300 \mathrm{msec}$ (Fig. $2 A 2, B 1$ ). In the presence of $1 \mu \mathrm{M}$ TTX, the fast sodium spikes were blocked, and a clear LTS was revealed (Fig. 2B2). This LTS was similar to responses described in other areas of guinea-pig neocortex (Friedman and Gutnick, 1987; Sutor and Zieglgänsberger, 1987; Montoro et al., 1988) and, although less powerful, similar to the LTS described in thalamus and inferior olive.

\section{Presence of LTS in MFC pyramidal neurons}

We could separate two groups of cells within guinea-pig MFC based on the presence of this LTS. Those cells with LTS (LTS+; Fig. $3 A$ ) generated a powerful rebound response at the break of a hyperpolarizing current pulse of $450 \mathrm{msec}$ (or longer) applied from a membrane potential of -55 to $-60 \mathrm{mV}$ (Fig. 3A1); after the application of TTX $(1 \mu \mathrm{M})$, the LTS was revealed as a slow spike of $15-25 \mathrm{mV}$ of amplitude (Fig. 3A2) following a current pulse that hyperpolarized the cell below $-75 \mathrm{mV}$. Those cells without LTS (LTS-; Fig. 3B) had a passive response at the break of the current pulse in control extracellular solution and in the presence of TTX (Fig. 3B1,B2). In response to depolarizing current pulses in the presence of TTX $(1 \mu \mathrm{M})$ and TEA $(5 \mathrm{~mm})$, both groups of neurons generated high-threshold calcium spikes (Fig. $3 A 3, B 3)$, which were easily differentiated from the LTS given their differences in threshold, amplitude, and time course. Approximately one-half of the recorded neurons had LTS (53\% LTS + vs $47 \%$ LTS-); however, the distribution of LTS + and LTS - neurons within MFC was very different (see below). 


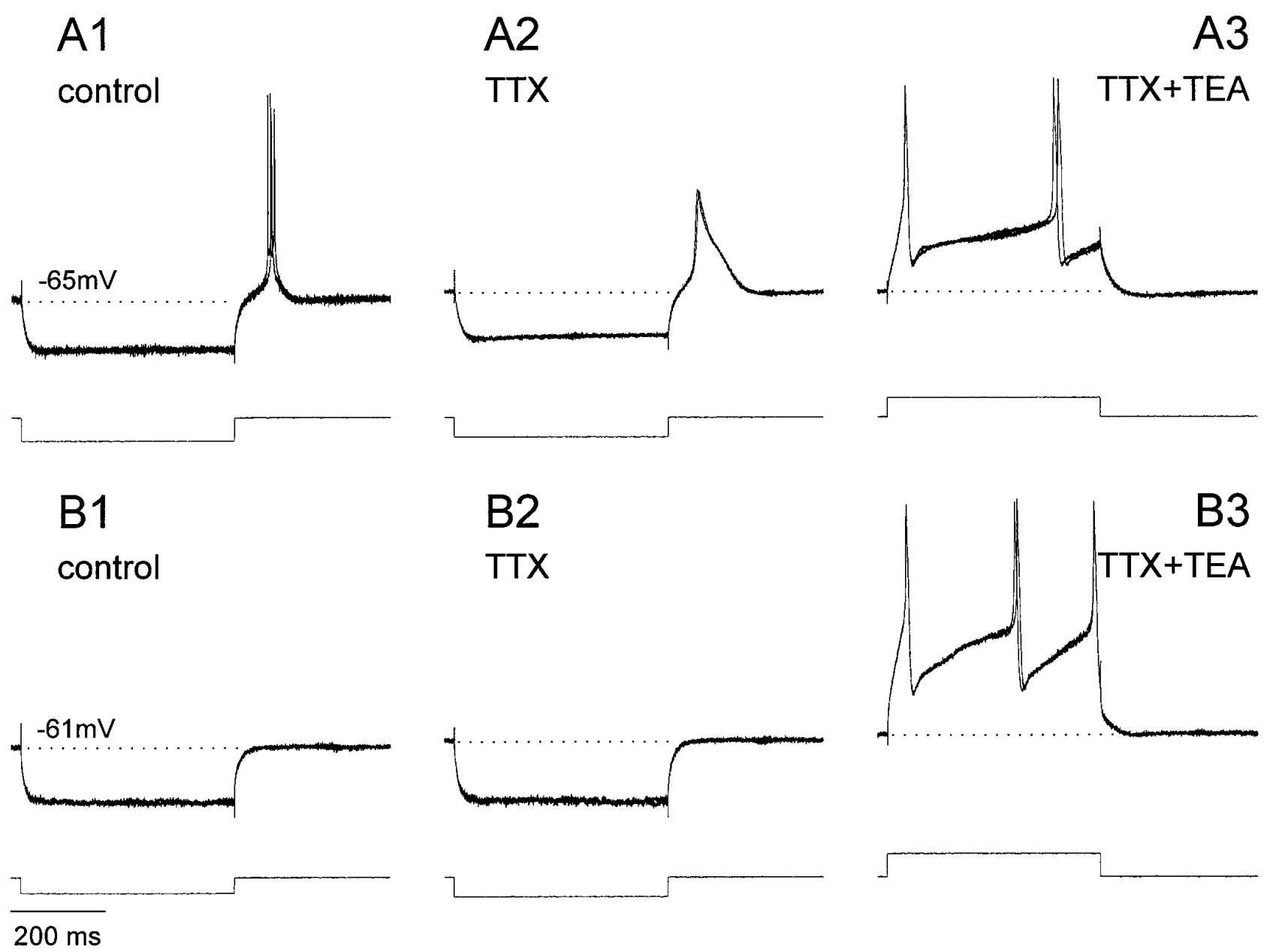

Figure 3. Electrophysiological responses of LTS + and LTS - neurons. Responses of an LTS + neuron $(A$; recording electrode at $860 \mu \mathrm{m}$ from the pia) and an LTS - neuron $(B$; recording electrode at $360 \mu \mathrm{m}$ from the pia) to hyperpolarizing and depolarizing current pulses applied from the resting membrane potential (dotted lines). Recordings obtained in control extracellular solution ( $A 1$ and $B 1)$, in the presence of $1 \mu \mathrm{M}$ TTX (A2 and B2), and in the presence of $1 \mu \mathrm{M}$ TTX and $5 \mu \mathrm{M}$ TEA ( $A 3$ and $B 3)$. Two consecutive sweeps are shown in each panel. Scale bars in $B 1$ apply to all panels.

\section{LTS is generated by the LTCC}

The current underlying the LTS was recorded with dSEVC. In the presence of TTX $(1 \mu \mathrm{M})$ and TEA $(10 \mathrm{mM})$ used to block voltage-dependent sodium and potassium currents, depolarizing pulses of $100-150 \mathrm{msec}$ were applied from a holding potential of -80 to $-90 \mathrm{mV}$. Figure 4 illustrates representative voltage-clamp recordings taken from an LTS + neuron (Fig. $4 A$ ) and from an LTS - neuron (Fig. 4B) in response to stepped voltage pulses from -85 to $-38 \mathrm{mV}$; the LTS + neuron showed a transient inward current that was totally absent in the LTS - neuron. This difference is clear when we compare the averaged $I-V$ plots of nine LTS + cells and seven LTS - cells (Fig. 4C). In the LTS- neurons, there were no voltagedependent currents between -60 and $-40 \mathrm{mV}$, whereas in LTS + neurons there was a large and clear inward current activated in this voltage range. In LTS - neurons, depolarizations to potentials more positive than -35 or $-40 \mathrm{mV}$ evoked high-threshold noninactivating (or slowly inactivating) calcium currents (see Fig. 4C, open circles) that were not studied further. The properties of transient inward currents recorded in LTS + cells are illustrated in Figure 5. The current started to activate at membrane potentials close to $-60 \mathrm{mV}$ (Fig. $5 B$ ) and inactivated completely after $40-60 \mathrm{msec}$ (Fig. $5 A, C$ ); this in- activation was voltage-dependent and occurred in a membrane potential range of -65 to $-90 \mathrm{mV}$ (Fig. $5 D, E$ ). The pharmacological properties of this current are shown in Figure 6. It was blocked after the perfusion of the slice with calcium-free extracellular solution $(n=5$; Fig. $6 A$ ) or by low concentrations $(50-100 \mu \mathrm{M})$ of extracellular $\mathrm{Ni}^{2+}(n=7$; Fig. $6 B)$. Drugs that block high-voltage-activated $\mathrm{Ca}^{2+}$ currents were also tested. Nimodipine applied at concentrations of 3-10 $\mu \mathrm{M}(n=4$; Fig. $6 C)$ produced no effect or a slight decrease of the transient current $(<15 \%$ of the peak value). Finally, a mixture of $\omega$-conotoxin GVIA (20 mM), $\omega$-conotoxin MVIIC (20 $\mu \mathrm{M})$, and $\omega$-agatoxin IVA (200 nM) did not affect the transient current $(n=3$; Fig. $6 D)$. All these properties are typical of the LTCC recorded in thalamic relay neurons (Coulter et al., 1989; Crunelli et al., 1989), isolated neocortical pyramidal neurons (Sayer et al., 1990, 1993), and isolated immature pyramidal neurons from hippocampus (Thompson and Wong, 1991), including the partial sensitivity to dihydropyridines that, although not a characteristic of LTCCs, has been reported in other mammalian central neurons, including cortical neurons (Akaike et al., 1989; Sayer et al., 1990). The electrophysiological properties of this current were also consistent with the characteristics of the LTS recorded in current clamp. 

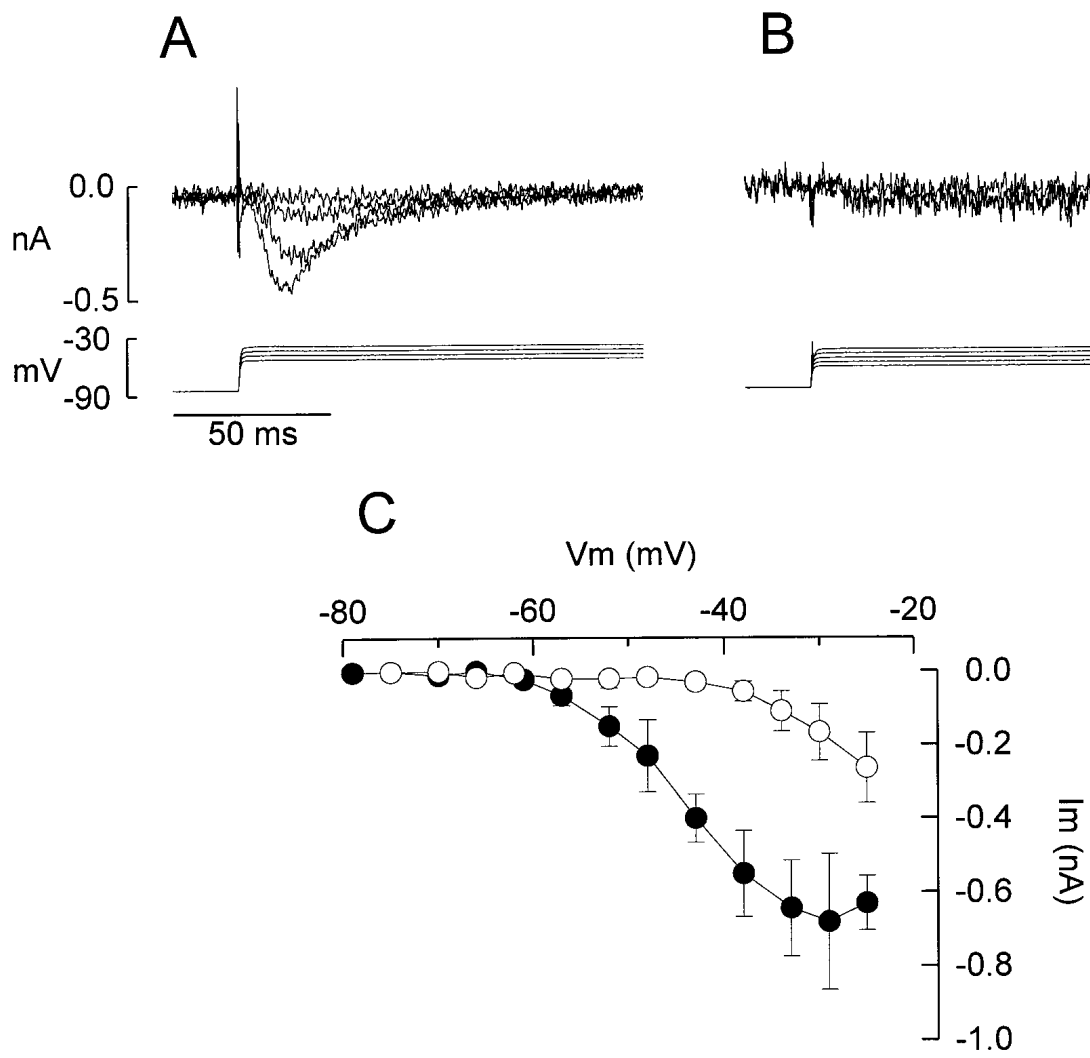

A
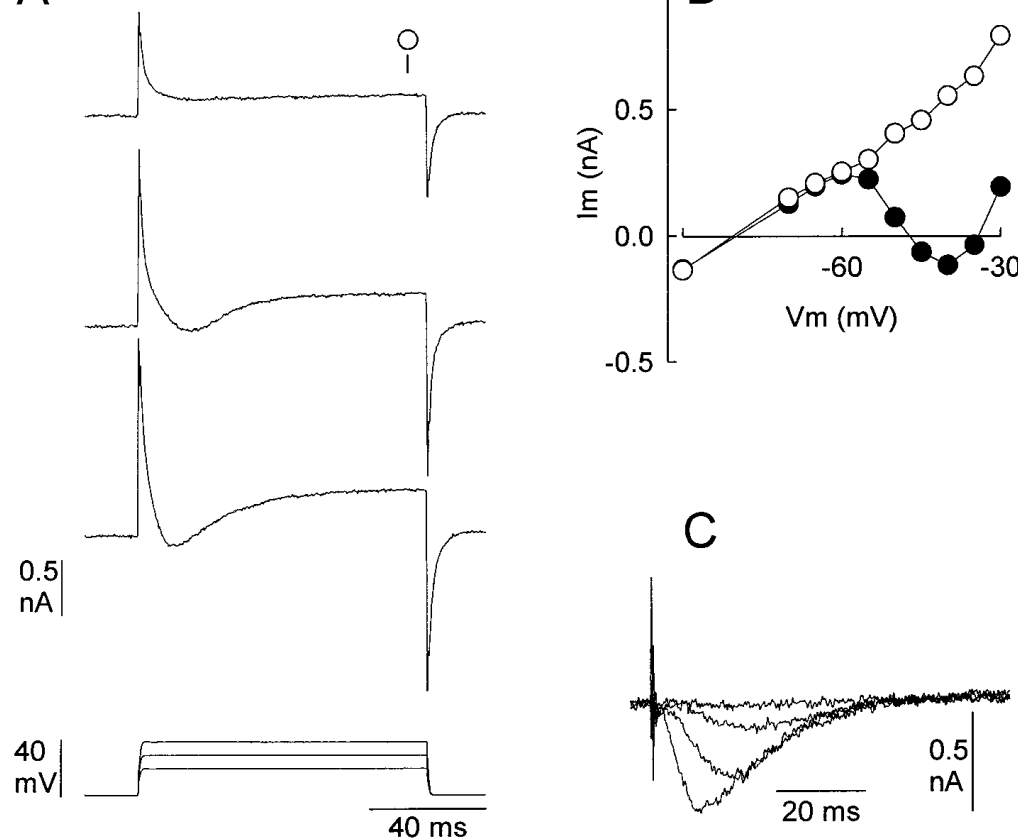

B
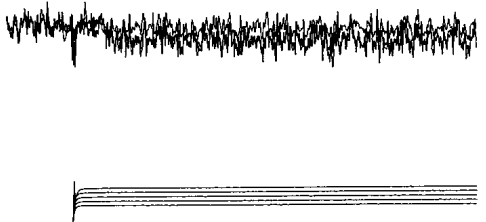

Figure 4. Transient inward currents in LTS + and LTS - neurons. $A, B$, Membrane currents (top traces) evoked by depolarizing voltage pulses (bottom traces) applied from $-85 \mathrm{mV}$ in an LTS + neuron $(A$, electrode at $790 \mu \mathrm{m}$ from the pia) and in an LTS - neuron $(B$, electrode at $360 \mu \mathrm{m}$ from the pia). The recordings were obtained in the presence of TTX $(1 \mu \mathrm{M})$ and TEA $(10 \mathrm{mM})$ and with a CsCl-filled electrode; each trace is the average of five consecutive recordings, and the linear components were subtracted by appropriate scaling of the response to small hyperpolarizing voltage pulses. Scale bars in $A$ apply to $B$. $C$, Averaged peak $I-V$ plots built from recordings similar to $A$ and $B$ obtained from nine LTS + neurons (filled circles) and seven LTS - neurons (open circles); data points are mean \pm SEM. The holding potential of all neurons used to make this plot was kept between -85 and $-90 \mathrm{mV}$.
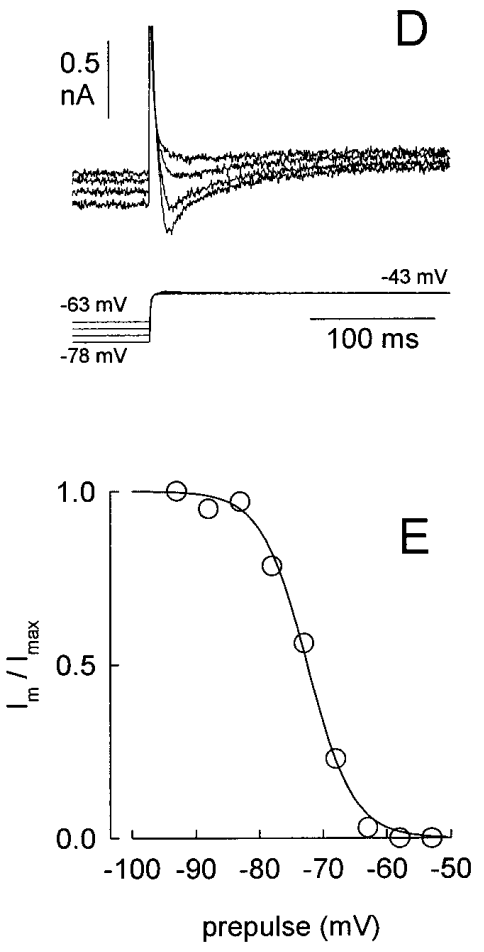

Figure 5. Properties of the transient inward current recorded in LTS + neurons. A, Representative raw membrane currents (top traces) recorded in an LTS+ neuron (electrode at $860 \mu \mathrm{m}$ from the pia) evoked by depolarizing voltage pulses from $-80 \mathrm{mV}$ (bottom traces) in the presence of TTX ( $1 \mu \mathrm{M})$ and TEA ( 10 mM). $B, I-V$ relationship of the recordings shown in $A$. The current was measured at the inward peak (filled symbols) and at the end of the voltage pulse (open symbols; time of measurement marked by the open symbol in $A$ ); note that the $I-V$ plot at the end of the pulse was almost linear up to $-40 \mathrm{mV}$. $C$, Transient inward current isolated from the recordings shown in $A$ after subtraction of the leakage currents; the largest current shown was elicited by a depolarization to $-40 \mathrm{mV}$. D , Steady-state inactivation measured in a different cell (electrode at $800 \mu \mathrm{m}$ from the pia). Currents (top traces) evoked by voltage steps from different levels to $-43 \mathrm{mV}$ (bottom traces). E. Plot of the peak inward currents shown in $D$ (relative to the maximum) versus the prepulse voltage. The continuous line is the best fit to the data of a Boltzmann distribution of the form $I / I_{\max }=1 /\left(1+\exp \left(\left(V_{\mathrm{m}}-V_{1 / 2}\right) / k\right)\right)$, where $V_{1 / 2}=-72.5 \mathrm{mV}$ and $k=3.6 \mathrm{mV}$. All current traces of this figure are the average of five consecutive recordings. The two cells shown in this figure were recorded with CsCl-filled electrodes. 


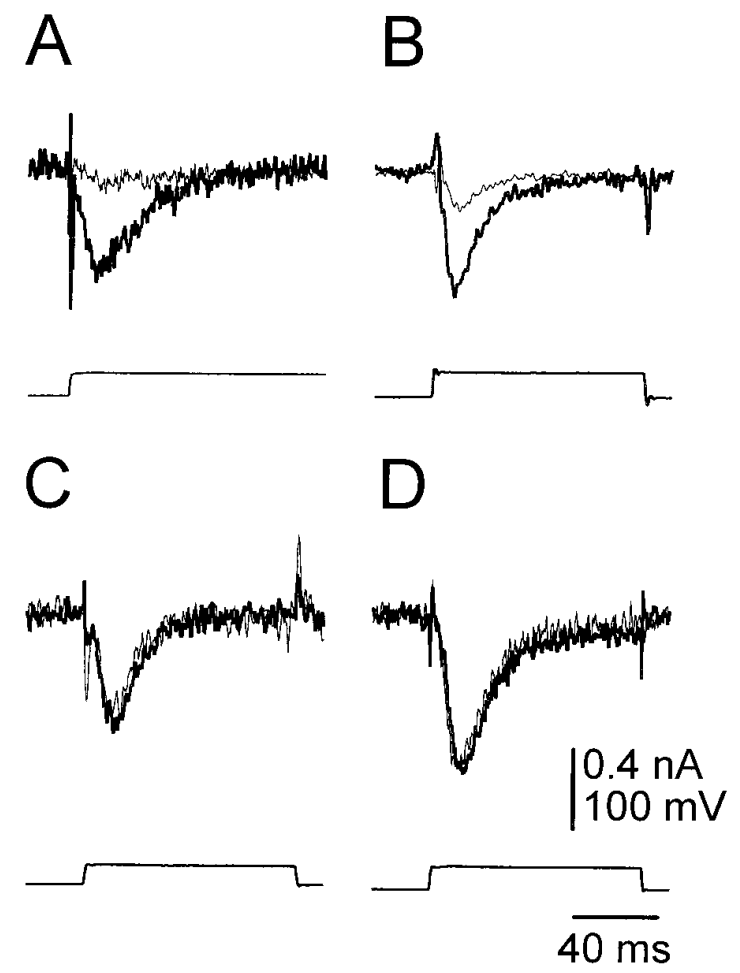

Figure 6. Pharmacological properties of the transient current recorded in LTS + neurons. Each panel shows the currents (top traces; control currents are the thick traces) recorded in response to depolarizing pulses applied from a holding potential of $-80 \mathrm{mV}$ (bottom traces) after removal of linear components. $A$, Block of the transient current by perfusion with $\mathrm{Ca}^{2+}$-free extracellular solution. $B$, Reduction of the current by $50 \mu \mathrm{M}$ extracellular $\mathrm{Ni}^{2+}$. $C$, Effect of $10 \mu \mathrm{M}$ nimodipine. $D$, The application of a solution containing a mixture of $\omega$-conotoxin GVIA $(20 \mu \mathrm{M})$, $\omega$-conotoxin MVIIC $(20 \mu \mathrm{M})$, and $\omega$-agatoxin IVA $(200 \mathrm{nM})$ did not affect the transient current. Recordings of each panel are from different cells. (In all cases, the recording electrode was between 700 and $900 \mu \mathrm{m}$ from the pia.)

\section{Distribution of LTS+ and LTS - neurons within MFC}

The distribution of LTS + and LTS - cells within MFC is shown in Figure 7. LTS + neurons were found only in middle and deep layers of the cortex (starting at $500 \mu \mathrm{m}$ from the pial surface), being most frequent $700-1200 \mu \mathrm{m}$ from the pial surface and almost totally absent in a cortical band of $400 \mu \mathrm{m}$ thickness lying just below layer I (Fig. $7 B)$. Only $2.5 \%$ of the recorded LTS + neurons were located between 250 and $600 \mu \mathrm{m}$ (approximately layers II/III), and this was 5\% of the recorded cells in these layers, whereas $97.5 \%$ were located between 600 and $1300 \mu \mathrm{m}$ (layers V/VI), which was $68 \%$ of the cells recorded in these layers. In contrast, LTS - neurons were found at all depths within MFC, most frequently in superficial layers (Fig. $7 A$ ); note that $50 \%$ of LTS - neurons were between 250 and $600 \mu \mathrm{m}$ and $50 \%$ were between 600 and $1300 \mu \mathrm{m}$. The distributions of LTS + and LTSneurons (Figs. 7A, $B$ ) were statistically different ( $p<0.0001$, MannWhitney rank sum test). Figure 7, $C$ and $D$, shows the distribution of a sample of 36 neurons recorded in voltage clamp and separated into two groups according to the presence or absence of the LTCC (see the insets in Fig. 7C,D). These distributions were statistically different $(p<0.002$, Mann-Whitney rank sum test) and very similar to the distributions of the LTS + and LTS - neurons. The distributions of LTS- neurons and neurons without LTCC (Fig. 7A,C) were not statistically different (compared with the Mann-Whitney rank sum test) and their medians were similar (490 and $570 \mu \mathrm{m}$, respectively). The distributions of LTS + neurons and neurons with T calcium current also were not different (Fig. 7B,D; medians 815 and $800 \mu \mathrm{m}$, respectively).

The distribution of LTS + and LTS - cells might be distorted by several factors, such as the relative undersampling of neurons in deep layer VI (deeper than 1200-1300 $\mu \mathrm{m}$ ) not only because of the lower density of cells and the larger amount of fibers in this area, but also because of the variation in thickness of the MFC in different slices, ranging from 1100 to $1300 \mu \mathrm{m}$. Another possible source of error is our assumption that the measured position of the recording electrode through the calibrated eyepiece is an accurate estimate of the position of the neuronal soma. We believe our assumption is correct because the position of the electrode, measured at the time of recording, always matched the position of the soma of Neurobiotin-stained neurons.

\section{Morphological characteristics of LTS- and LTS+ neurons}

To study neuronal morphology, 41 cells located at different depths in MFC were intracellularly stained with Neurobiotin. All of them had electrophysiology of the RS type and were pyramidal in shape with clear apical dendrites that reached layer I (Fig. 8). The stained neurons, the cell bodies of which were no deeper than 600 $\mu \mathrm{m}$ from the pial surface $(n=7)$, had short apical dendrites that branched extensively in layer I. None of them had LTS in the presence of TTX (Fig. $8 A$ ). Those neurons whose cell bodies were located deeper in the cortex also had a clear pyramidal shape, and the general morphological appearance of those with $(n=21)$ and without $(n=13)$ LTS was similar (Fig. $8 B, C)$. However, some important differences, mostly related to the size and morphology of the apical dendrite, were found when measuring morphological parameters. The overall shape and size of the dendritic tree in LTS + and LTS - neurons was clearly different (Fig. 8B,C). To quantify these differences, we used several parameters (Table 1); as an estimate of the dendritic size, we measured the total number of branches, the total dendritic length, and the diameter of the main shaft. The values of these parameters showed that apical dendritic trees were shorter and much thinner in LTS + neurons (Table 1). Furthermore, the apical dendritic tree of LTS + neurons was less ramified as shown by the parameters used to quantify the degree of branching (number of terminal branches and number of branching points; Table 1 and Fig. 8). These differences were restricted to the apical dendritic tree, because the degree of branching of the basal dendrites was similar in both classes of cells (Table 1). The cells shown in Figure 8, $B$ and $C$, are representative of the LTS + and LTS - cells, respectively, because their values of the parameters of dendritic complexity are very similar to the average values of the samples of LTS + and LTScells given in Table 1. In particular, the apical dendrite of the cell in Figure $8 B$ has 10 terminal branches, 9 branching points, 17 branches, and a total length of $1976 \mu \mathrm{m}$, and the values for the apical dendrite of the cell in Figure $8 C$ are 16, 15, 31, and 2697 $\mu \mathrm{m}$, respectively.

Despite the differences in dendritic structure, the somatic size was similar in both neuronal types: the maximum somatic diameter and somatic area averaged 17.6 $\pm 0.66 \mu \mathrm{m}$ and $183.8 \pm 11.2$ $\mu \mathrm{m}^{2}$ in LTS $+(n=21)$ and $18.4 \pm 1.22 \mu \mathrm{m}$ and $196.9 \pm 23.6 \mu \mathrm{m}^{2}$ in LTS - neurons $(n=13)$.

\section{Electrophysiological differences between LTS + and LTS- neurons}

To study other possible differences associated with the presence of a low-threshold spike, we compared the general electrophysiolog- 


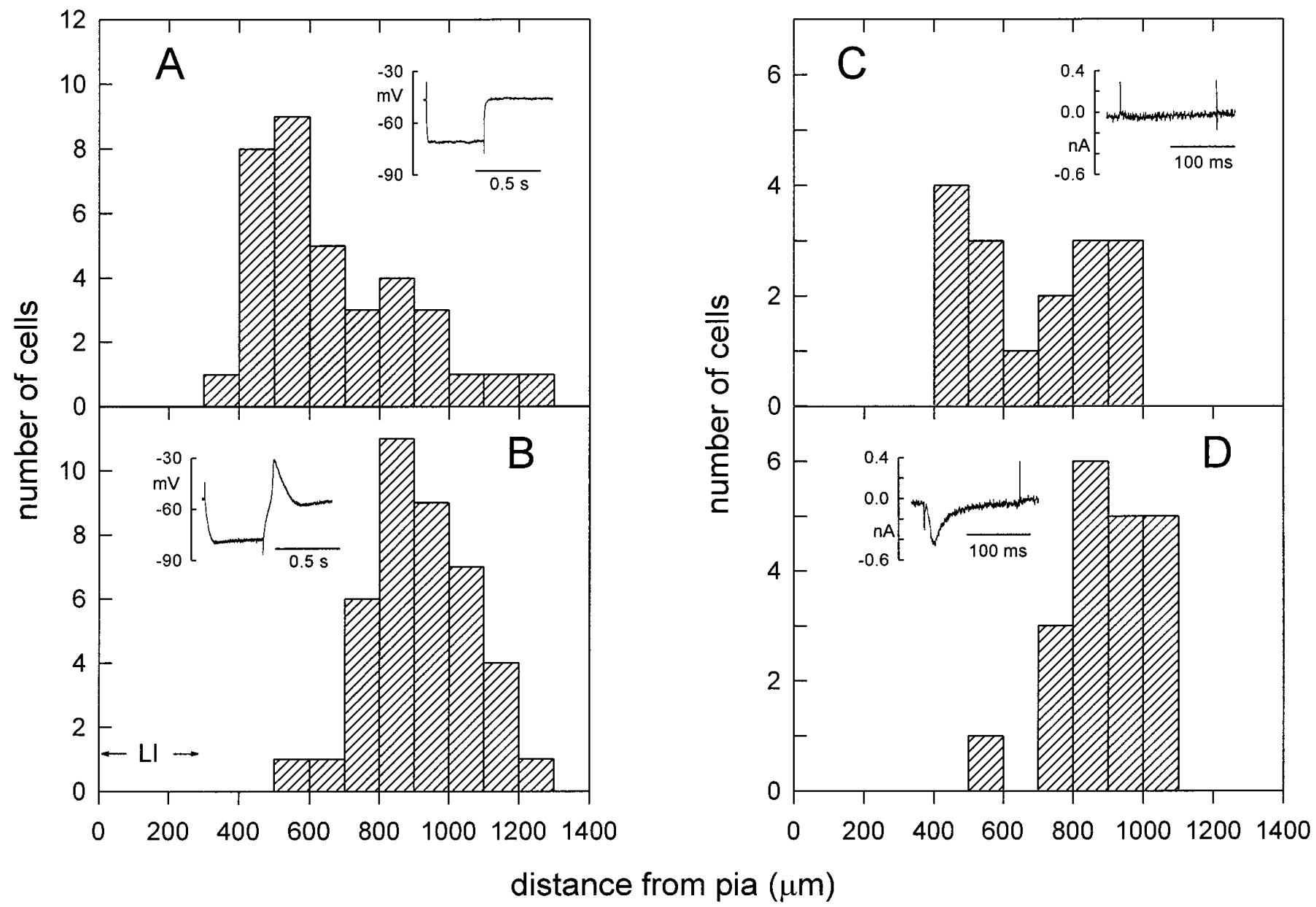

Figure 7. Laminar localization of neurons in MFC. Number of LTS- $(A)$ and LTS $+(B)$ neurons recorded at different depths in MFC; the insets show representative recordings of both types of neurons obtained in response to hyperpolarizing current pulses in the presence of TTX. Note the almost complete absence of LTS + neurons up to $\sim 600 \mu \mathrm{m}$ down the pial surface. Layer I $(L I)$ spanned approximately the band between 0 and 200-250 $\mu \mathrm{m}$. $C$, $D$, Number of neurons found at different depths that under dSEVC did not have $(C)$ or had $(D)$ an LTCC as described in Figures 4 and 5. The insets show the current recorded in one neuron of each class in response to a voltage step from $-85 \mathrm{mV}$ to $-40 \mathrm{mV}$ in the presence of TTX and TEA.

ical properties and synaptic responses of LTS + and LTS - neurons. For this comparison, we selected a sample of 26 LTS+ neurons and 18 LTS - neurons, the cell bodies of which were located at approximately the same depth in the cortex (between 700 and $900 \mu \mathrm{m}$ from the pial surface, estimated from the position of the recording electrode). Resting membrane potential and input resistance were similar in both groups of neurons, but the action potential characteristics were different: LTS + neurons fired action potentials of lower amplitude and longer duration than LTS - neurons (Table 2).

We also studied the synaptic responses elicited by the stimulation of layer I (subpial region) in the radial column where the impaled cell was located. Figure 9 illustrates the complex sequence of synaptic potentials elicited by stimulation of layer I, with a brief EPSP truncated by a slow IPSP that lasted 300-400 msec (Fig. 9A,B). The IPSP had two components: an early component that reversed between -55 and $-60 \mathrm{mV}$ and a late and much more prolonged component that reversed between -70 and $-80 \mathrm{mV}$ (Fig. 9C). This sequence of synaptic potentials is very similar to the response evoked by stimulation of the white matter (Higashi et al., 1991) and intracortical layers (Sutor and Hablitz, 1989). The early and late IPSPs probably were associated with the activation of $\mathrm{GABA}_{\mathrm{A}}$ and $\mathrm{GABA}_{\mathrm{B}}$ receptors, respectively (Connors et al., 1988). This synaptic response was very similar in both LTS + and LTS - neurons, but the amplitude of the late IPSP (measured at $-55 \mathrm{mV}$ ) was much larger in LTS+ neurons, whereas the amplitude of the early component was similar in both groups (Fig. 9D). In spite of its amplitude being larger in LTS+ neurons, the late component was always too small to deactivate the LTCC and generate a rebound response. Stimulation of the white matter underlying the site of recording $(n=3)$ also generated a very similar sequence of early and late IPSPs, but the late component also was unable to generate rebound responses in LTS + neurons.

\section{DISCUSSION}

The results presented here show that some pyramidal neurons in guinea-pig MFC were able to fire LTS and that these spikes were generated by a voltage-dependent current similar to the LTCC described in peripheral (Carbone and Lux, 1987; Fox et al., 1987) and central neurons (Coulter et al., 1989; Crunelli et al., 1989). Furthermore, the pyramidal neurons able to generate these LTS (and therefore endowed with the LTCC) were very precisely located within MFC, rarely found in layers II/III and very fre- 

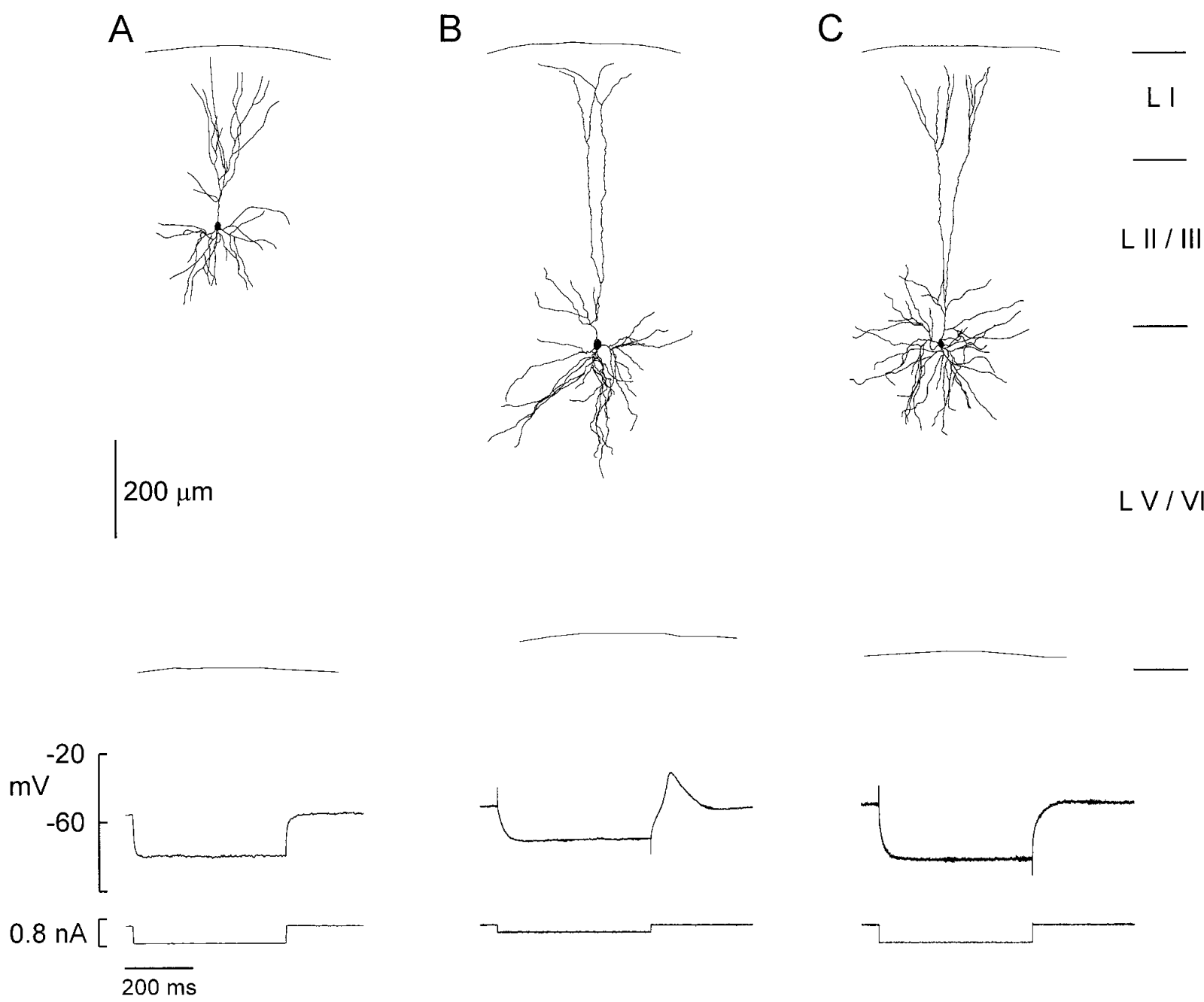

Figure 8. Morphology of LTS+ and LTS - neurons. Drawings of three neurons recorded in MFC and intracellularly stained with Neurobiotin. Their respective responses to hyperpolarizing current pulses in the presence of TTX are shown at the bottom of each drawing. Cells $A$ and $C$ are LTS - , and cell $B$ is LTS + . The approximate limits between layers are shown.

quently found in layers V/VI. As well as this localization, LTS + neurons recorded in layers V/VI had some important morphological and physiological differences from those unable to generate LTS. These demonstrate that LTCCs are present in subsets of pyramidal neurons of guinea-pig MFC. The restricted localization of the LTCC appears not to be a general property of calcium currents because other types, such as the L-type, are present in all callosal and colliculus-projecting neurons of the visual cortex (Giffin et al., 1991). The firing of LTS and their generation by LTCC is well documented in other areas of the brain such as the thalamus (Crunelli et al., 1989) and, apart from the guinea-pig MFC described here, the presence of LTS has been reported with no reference to the localization of the cells in human neocortex (Foehring and Waters, 1991), rat neocortex (Sutor and Zieglgänsberger, 1987) guinea-pig parietal neocortex (Friedman and Gutnick, 1987), and guinea-pig visual cortex (Montoro et al., 1988).

The presence of LTCC in the middle and deep layers of the cortex may be implicated in several physiological functions. First, it may be related to the site of origin of some forms of rhythmic activity in the cerebral cortex; thus, in rat neocortex, oscillatory activity in the range of 5 to $10 \mathrm{~Hz}$ is originated in layer $\mathrm{V}$ pyramidal neurons (Silva et al., 1991). Second, the presence of
LTS in some cortical neurons may be related to the thalamocortical pathway, contributing to the synchronization of cortex and thalamus during the generation of slow oscillations (spindles) in slow-wave sleep (for review, see Steriade and Llinás, 1988). In fact, it has been shown that low voltage-activated calcium current is present in different proportions of pyramidal neurons isolated from rat visual cortex, depending on their projection site (Giffin et al., 1991). Finally, the location of pyramidal neurons with LTCC may have a developmental significance because those cells that do not have the current are superficial cells, which differentiate and migrate later in development (for review, see Rakic, 1995).

\section{Electrophysiological properties and generation of bursts}

Pyramidal neurons recorded in isocortical areas have been shown to differ in the patterns of action potential firing that they generate in response to the injection of current pulses (Connors et al., 1982; McCormick et al., 1985; Connors and Gutnick, 1990). Most pyramidal neurons (RS neurons) generate a single spike when stimulated with a just-threshold current pulse; as the stimulus amplitude increases, RS cells fire tonically with frequency adaptation. The degree of frequency adaptation is variable among 


\begin{tabular}{|c|c|c|}
\hline & LTS + neurons & LTS - neurons \\
\hline \multicolumn{3}{|l|}{ Apical dendrite } \\
\hline \multicolumn{2}{|l|}{ Diameter of the main trunk } & $2.8 \pm 0.31(13)^{* *}$ \\
\hline Number of terminal branches & $10.8 \pm 0.5(5)^{*}$ & $19.6 \pm 2.9(5)^{*}$ \\
\hline Number of branching points & $9.8 \pm 0.45(5)^{*}$ & $18.6 \pm 2.9(5)^{*}$ \\
\hline Total length $(\mu \mathrm{m})$ & $1632 \pm 229(5)^{* *}$ & $2688 \pm 173(5)^{* *}$ \\
\hline Total number of branches & $19.6 \pm 1.1(5)^{*}$ & $36.8 \pm 4.9(5)^{*}$ \\
\hline \multicolumn{3}{|l|}{ Basal dendrites } \\
\hline \multicolumn{3}{|l|}{ Diameter of primary dendrites } \\
\hline$(\mu \mathrm{m})$ & $1.45 \pm 0.09(47)$ & $1.60 \pm 0.08(45)$ \\
\hline Number of terminal branches & $30.6 \pm 4.1(5)$ & $32.0 \pm 3.2(5)$ \\
\hline Number of branching points & $25.6 \pm 3.9(5)$ & $27.2 \pm 2.6(5)$ \\
\hline Total length $(\mu \mathrm{m})$ & $3370 \pm 491(5)$ & $3364 \pm 283(5)$ \\
\hline Total number of branches & $57.2 \pm 8.3(5)$ & $63.4 \pm 4.4(5)$ \\
\hline
\end{tabular}

${ }^{*} p<0.02 ; * * p 0.01$.

The diameter of the dendrites was measured $10-20 \mu \mathrm{m}$ from the soma, at a point where it became uniform. The total number of branches was calculated considering individual branches as the segments between branching points, including the terminal segments (segments not ending in a branching point). The total dendritic length was computed as the sum of the lengths of individual branches. Values given as mean $\pm \operatorname{SEM}(n)$. The statistical significance of the differences was calculated with the Student's $t$ test except the values of diameter of apical and basal dendrites. The values of these parameters did not meet the criteria for normal distribution and were compared with the Mann-Whitney rank sum test, being the medians of the apical dendrite $1.80 \mu \mathrm{m}(\mathrm{LTS}+$ ) and $2.20 \mu \mathrm{m}$ (LTS-) and of the basal dendrites $1.30 \mu \mathrm{m}$ (LTS+) and $1.54 \mu \mathrm{m}$ (LTS-).

different subsets of RS cells (Chagnac-Amitai and Connors, 1989; Agmon and Connors, 1992). A small population of pyramidal cells (IB cells) generates a burst of action potentials in a stereotyped pattern that consists of three or more fast spikes arising from a slow afterdepolarization. IB cells are rare, found only in certain cortical laminae, and have slight morphological differences from regular spiking cells (Chagnac-Amitai et al., 1990; Mason and Larkman, 1990). The neurons included in our sample had electrophysiological properties homogeneous and consistent with those of the regular spiking type based on their firing pattern (Fig. 2), duration of their action potentials (Table 2), and the absence of bursts generated from the resting membrane potential. Only two or three typical bursting cells were recorded in a sample of more than 250 cells, and the only kind of bursting-like response that we have found in guinea-pig MFC is that associated with the presence of LTS (see Figs. 2B1,3A1). This finding, along with the fact that the distribution of LTS + cells in MFC resembles that of IB cells in neocortex (Connors and Gutnick, 1990), raises the possibility that in guinea-pig MFC (and in other allocortical areas), the generation of bursts depends only on the LTCC, whereas in cortical areas with isocortical structure, bursting depends on different and perhaps more complex ionic mechanisms. In agreement with this hypothesis, IB cells recorded in layer V of guinea-pig isocortex (sensorimotor cortex) did not have the LTCC (E. de la Peña and E. Geijo-Barrientos, unpublished results).

\section{Morphological and physiological differences between LTS + and LTS- neurons}

The morphological and physiological properties of LTS + neurons suggest that they form a separate group within the general class of regular spiking cells. In our study, LTS + cells had apical dendrites thinner, shorter, and less ramified than LTS - cells (Table 1, Fig. 8) and had action potentials of smaller amplitude and longer duration (Table 2) than LTS- cells. These characteristics make
Table 2. Electrophysiological properties of LTS+ and LTS-

\begin{tabular}{lll} 
& LTS + neurons & LTS - neurons \\
\hline $\begin{array}{l}\text { Membrane potential }(\mathrm{mV}) \\
\text { Action potential amplitude } \\
(\mathrm{mV})\end{array}$ & $-57.0 \pm 0.96(26)$ & $-57.4 \pm 1.42(18)$ \\
Action potential duration & $71.4 \pm 1.67(26)^{*}$ & $77.1 \pm 1.83(18)^{*}$ \\
$\quad(\mathrm{msec})$ & $1.52 \pm 0.09(26)^{a}$ & $1.19 \pm 0.08(18)^{a}$ \\
Input resistance $(\mathrm{M} \Omega)$ & $66.0 \pm 6.42(26)$ & $57.3 \pm 5.49(18)$ \\
\hline
\end{tabular}

${ }^{*} p<0.05$ (Student's $t$ test).

${ }^{a}$ The distributions of this parameter did not meet the criteria for normal distribution and were compared with the Mann-Whitney rank sum test, being the difference significant ( $p<0.02$; medians $1.40 \mathrm{msec}$, LTS + and $1.10 \mathrm{msec}$, LTS - ).

The amplitude of the action potentials was measured from the threshold level, and the duration was measured at half-amplitude. The input resistance was measured from the response to small $(-0.1 \mathrm{nA})$ hyperpolarizing current pulses. Values are given as mean $\pm \operatorname{SEM}(n)$.

LTS + cells very different from the other neuronal type able to generate bursting, the IB cells, which have almost the opposite characteristics. IB cells have extensive apical and basal dendritic trees, and the thickness of their main apical trunk is almost twice that of RS cells (Chagnac-Amitai et al., 1990). In spite of their different shapes, the input resistance of LTS + and LTS - neurons was similar. In rat frontal cortex, nonpyramidal neurons that fire LTS have higher input resistance that those that do not (Kawaguchi, 1993), although in this case the difference in input resistance is associated with differences in overall neuronal shape. According to Kawaguchi (1993), pyramidal neurons may also be divided into high and low input resistance groups, but none of them generate LTS or bursts of action potentials.

\section{Differences in IPSPs}

Besides the generation of bursts of action potentials, LTCC determines the possibility of rebound firing at the end of inhibitory synaptic potentials. This has been clearly demonstrated in thalamic relay cells, which are able to fire at the end of inhibitory synaptic potentials generated by thalamic reticularis neurons [for example, see Huguenard and Prince (1994), their Fig. 8]. We never observed this rebound response in LTS + neurons from guinea-pig MFC. Although in these neurons the late component of the IPSP was larger than in LTS- neurons (see Fig. 9), it was never able to initiate a rebound firing of the LTS. The reason for this may be that the IPSP amplitude was not enough to deinactivate the LTCC or that the repolarization phase of the IPSP was too slow to activate it, given that the degree of activation of LTCC is very sensitive to the slope of the depolarization (Crunelli et al., 1989). Still, it is important to note that the conditions of extracellular stimulation in vitro used in these experiments may not be fully representative of the situation in vivo, where the synchronous activation of a large number of inhibitory fibers may generate IPSPs capable of initiating rebound firing in LTS + neurons. The difference in inhibitory synaptic potentials correlated to different intrinsic properties is supported by several studies. For example, activation of inhibitory interneurons by focal activation of acetylcholine induces a larger inhibitory effect on RS than on IB cells (McCormick and Prince, 1986). Also, there is some morphological evidence that different classes of pyramidal neurons receive different ratios of excitatory and inhibitory contacts (Hersch and White, 1981).

\section{Conclusion}

This work has clearly demonstrated that LTCC is present in a subset of pyramidal neurons in the guinea-pig MFC. These neu- 

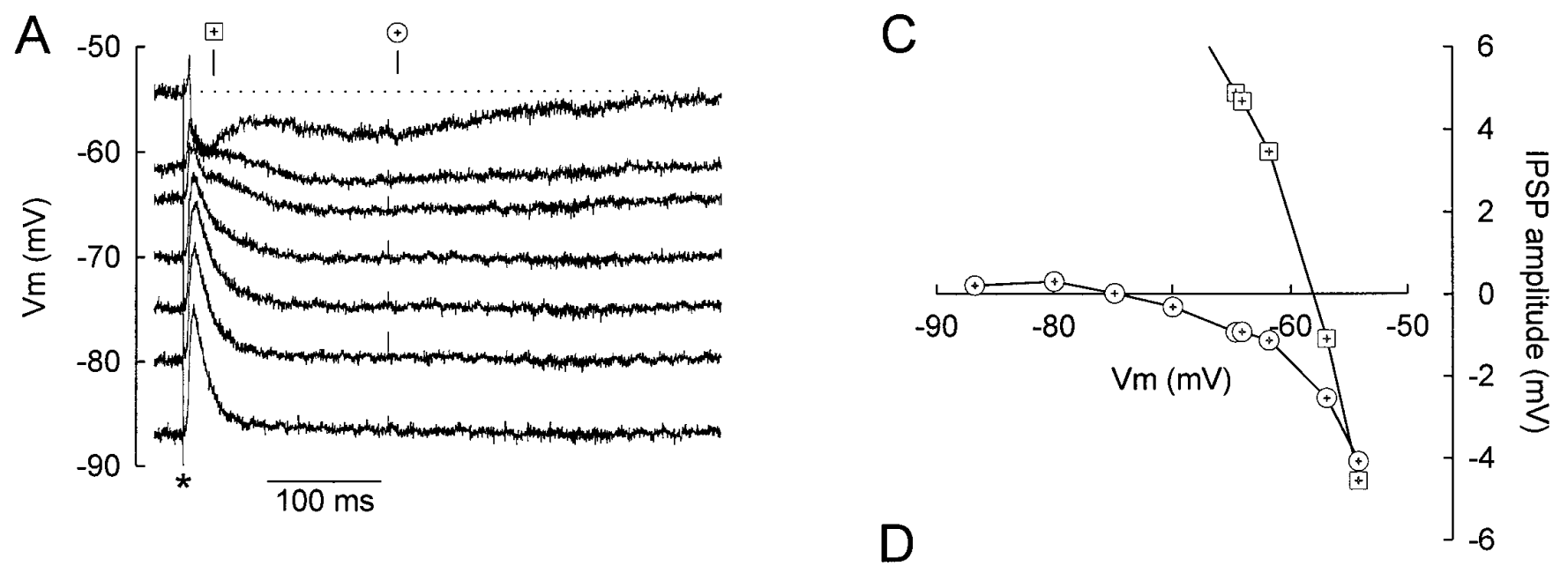

B
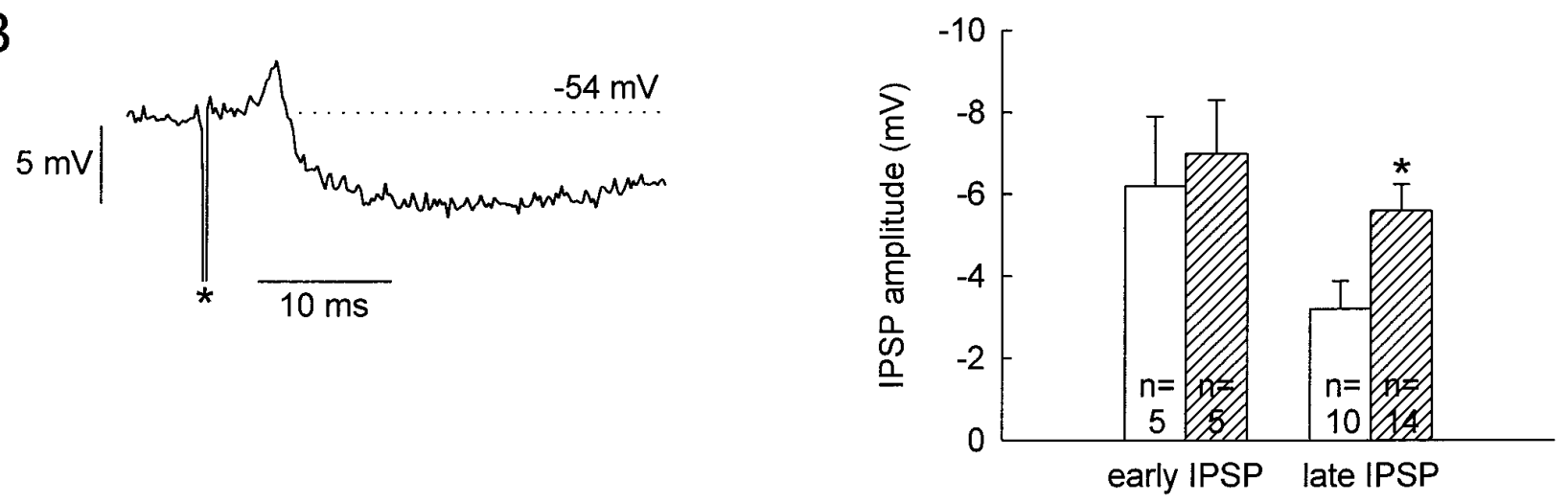

Figure 9. Synaptic potentials evoked by stimulation of layer I in MFC. $A$, Synaptic potentials recorded in an LTS + neuron (electrode at $815 \mu \mathrm{m}$ from the pia) at different membrane potentials. The asterisk shows the stimulus artifact, and the dotted line marks the membrane potential level of the more depolarized recording $(-54 \mathrm{mV})$; this recording is shown at larger voltage and time scale in $B$ to illustrate the EPSP and the early IPSP. $C$, Relationship between the amplitude of the early and late IPSPs (squares and circles, respectively) and the membrane potential obtained from the cell illustrated in $A$ and $B$. The amplitude of the synaptic potentials was measured at the times shown by the symbols in $A$. $D$, Amplitude of the early and late components of the IPSP (mean \pm SEM; number of cases on each bar) recorded in LTS - neurons (open bars) and LTS + neurons (hatched bars); the asterisk shows significant differences between the amplitudes of the late component in LTS + and LTS - neurons $(~ p<0.002$, Student's $t$ test).

rons are localized in middle and deep layers of the cortex and have well defined morphological and physiological properties, different from those of other pyramidal neurons in that area. These properties are the size and the degree of branching in the apical dendritic tree, the characteristics of the action potentials and the amplitude of the late component of the inhibitory synaptic potentials evoked by stimulation of layer I.

\section{REFERENCES}

Agmon A, Connors BV (1992) Correlation between intrinsic firing patterns and thalamocortical synaptic responses of neurons in mouse barrel cortex. J Neurosci 12:319-329.

Akaike N, Kostyuk PG, Osipchuk YV (1989) Dihydropyridine-sensitive low-threshold calcium channels in isolated rat hypothalamic neurones. J Physiol (Lond) 412:181-195.

Brown AM, Schwindt PC, Crill WE (1993) Voltage dependence and activation kinetics of pharmacologically defined components of highthreshold calcium current in rat neocortical neurons. J Neurophysiol 70:1530-1543.

Brown AM, Sayer RJ, Schwindt PC, Crill WE (1994) P-type calcium channels in rat neocortical neurones. J Physiol (Lond) 475:197-205.

Carbone E, Lux HD (1987) Kinetics and selectivity of a low-voltage activated calcium current in chick and rat sensory neurones. J Physiol (Lond) 386:547-570.

Chagnac-Amitai Y, Connors BW (1989) Synchronized excitation and inhibition driven by intrinsically bursting neurons in neocortex. J Neurophysiol 62:1149-1162.
Chagnac-Amitai Y, Luhmann HJ, Prince DA (1990) Burst generating and regular spiking layer 5 pyramidal neurons of rat neocortex have different morphological features. J Comp Neurol 296:598-613.

Connors BW, Gutnick MJ (1990) Intrinsic firing patterns of diverse neocortical neurons. Trends Neurosci 13:99-104.

Connors BW, Gutnick MJ, Prince DA (1982) Electrophysiological properties of neocortical neurons in vitro. J Neurophysiol 48:1302-1320.

Connors BW, Malenka RC, Silva LR (1988) Two inhibitory postsynaptic potentials, and $\mathrm{GABA}_{\mathrm{A}}$ and $\mathrm{GABA}_{\mathrm{B}}$ receptor-mediated responses in neocortex of rat and cat. J Physiol (Lond) 406:443-468.

Coulter DA, Huguenard JR, Prince DA (1989) Calcium currents in rat thalamocortical relay neurones: kinetic properties of the transient, low-threshold current. J Physiol (Lond) 414:587-604.

Crunelli V, Lightowler S, Pollard CE (1989) A T-type $\mathrm{Ca}^{2+}$ current underlies low-threshold $\mathrm{Ca}^{2+}$ potentials in cells of the cat and rat lateral geniculate nucleus. J Physiol (Lond) 413:543-561.

Finkel AS, Redman SJ (1985) Optimal voltage clamping with single microelectrode. In: Voltage and patch clamping with microelectrodes (Smith TG, Lecar H, Redman SJ, Gage PW, eds), pp 95-120. Bethesda, MD: American Physiological Society.

Foehring RC, Waters RS (1991) Contributions of low-threshold calcium current and anomalous rectifier $\left(I_{h}\right)$ to slow depolarizations underlying burst firing in human neocortical neurons in vitro. Neurosci Lett 124:17-21.

Fox AP, Nowycky MC, Tsien RW (1987) Kinetic and pharmacological properties distinguishing three types of calcium currents in chick sensory neurones. J Physiol (Lond) 394:149-172. 
Franz P, Galvan M, Constanti A (1986) Calcium-dependent action potentials and associated inward currents in guinea-pig neocortical neurons in vitro. Brain Res 366:262-271.

Friedman A, Gutnick MJ (1987) Low-threshold calcium electrogenesis in neocortical neurons. Neurosci Lett 81:117-122.

Geijo-Barrientos E, de la Peña E (1995) Localization of pyramidal neurons that have the T-type calcium current in guinea-pig prefrontal cortex. Soc Neurosci Abstr 21:1754.

Geijo-Barrientos E, Pastore C (1995) The effects of dopamine on the subthreshold electrophysiological responses of rat prefrontal cortex neurons in vitro. Eur J Neurosci 7:358-366.

Giffin K, Solomon JS, Burkhalter A, Nerbonne JM (1991) Differential expression of voltage-gated calcium channels in identified visual cortical neurons. Neuron 6:321-332.

Hersch SM, White EL (1981) Quantification of synapses formed with apical dendrites of Golgi-impregnated pyramidal cells: variability in thalamocortical inputs, but consistency in the ratios of asymmetrical to symmetrical synapses. Neuroscience 6:1043-1051.

Hess P (1990) Calcium channels in vertebrate cells. Annu Rev Neurosci 13:337-357.

Higashi H, Tanaka E, Nishi S (1991) Synaptic responses of guinea-pig cingulate cortical neurons in vitro. J Neurophysiol 65:822-833.

Huguenard JR, Prince DA (1994) Intrathalamic rhythmicity studied in vitro: nominal T-current modulation causes robust antioscillatory effects. J Neurosci 14:5485-5502.

Jahnsen H, Llinás R (1984) Electrophysiological properties of guinea-pig thalamic neurones: an in vitro study. J Physiol (Lond) 349:205-226.

Kawaguchi Y (1993) Groupings of nonpyramidal and pyramidal cells with specific physiological and morphological characteristics in rat frontal cortex. J Neurophysiol 69:416-431.

Llinás R (1988) The intrinsic electrophysiological properties of mammalian neurons: insights into central nervous system function. Science 242:1654-1664.

Llinás R, Yarom Y (1981) Electrophysiology of mammalian inferior olivary neurones in vitro. Different types of voltage-dependent ionic conductances. J Physiol (Lond) 315:549-567.

Mason A, Larkman A (1990) Correlations between morphology and electrophysiology of pyramidal neurons in slices of rat visual cortex. II. Electrophysiology. J Neurosci 10:1415-1428.

McCleskey EW (1994) Calcium channels: cellular roles and molecular mechanisms. Curr Opin Neurobiol 4:304-312.
McCormick DA (1990) Membrane properties and neurotransmitter actions. In: The synaptic organization of the brain (Shepherd GM, ed), pp 32-66. New York: Oxford UP.

McCormick DA, Prince DA (1986) Mechanisms of action of acetylcholine in the guinea-pig cerebral cortex in vitro. $\mathrm{J}$ Physiol (Lond) 375:169-194.

McCormick DA, Connors BA, Lighthall JW, Prince DA (1985) Comparative electrophysiology of pyramidal and sparsely spiny stellate neurons of the neocortex. J Neurophysiol 54:782-806.

Montoro RJ, López-Barneo J, Jassik-Gerschenfeld D (1988) Differential burst firing modes in neurons the mammalian visual cortex in vitro. Brain Res 460:168-172.

Rakic P (1995) A small step for a cell, a giant leap for mankind: a hypothesis of neocortical expansion during evolution. Trends Neurosci 18:383-388.

Sayer RJ, Schwindt PC, Crill WE (1990) High- and low-threshold calcium currents in neurons acutely isolated from rat sensorimotor cortex. Neurosci Lett 120:175-178.

Sayer RJ, Brown AM, Schwindt PC, Crill WE (1993) Calcium currents in acutely isolated human neocortical neurons. J Neurophysiol 69:1595-1606.

Silva LR, Amitai Y, Connors BW (1991) Intrinsic oscillations of neocortex generated by layer 5 pyramidal neurons. Science 251:432-435.

Steriade M, Llinás RR (1988) The functional states of the thalamus and the associated neuronal interplay. Physiol Rev 68:649-742.

Sutor B, Hablitz JJ (1989) EPSP in rat neocortical neurons in vitro. I. Electrophysiological evidence for two distinct EPSPs. J Neurophysiol 61:607-620.

Sutor B, Zieglgänsberger W (1987) A low-voltage activated, transient current is responsible for the time-dependent depolarizing inward rectification of rat neocortical neurons in vitro. Pflügers Arch 410:102-111.

Thompson SM, Wong RK (1991) Development of calcium current subtypes in isolated rat hippocampal pyramidal cells. J Physiol (Lond) 439:671-689.

Vogt BA, Peters A (1981) Form and distribution of neurons in rat cingulate cortex: areas 32, 24 and 29. J Comp Neurol 195:603-625.

Zilles K, Wree A (1985) Cortex: areal and laminar structure. In: The rat nervous system (Paxinos G, ed), pp 375-440. Marrickville, Australia: Academic. 